\title{
The thermotidal exciting function for water vapour absorption of solar radiation
}

\author{
M. BONAFEDE (*)
}

Received on May tith, 1976

\begin{abstract}
SUMMary. - The thermotidal exciting function $J$ is considered, for the absorption of solar radiation by water vapour, according to the model derived by siehert. The II ugge-Uloller formula for water vapour absorption is integrated numerically, using experimental data for the water vapour concentration in the troposphere and the stratosphere. It appears that Siebort's formula is a reasonable approximation at low tropospheric levels but it cramatically overestimates the water vapour thermotidal heating in the upper troposphere and in the stratosphere. It seems thus possible that, if the correct vertical profile is employed for $J$, the amplitudes and phases of the diurnal temperature oscillations and of the tidal wind speeds may sufter significant changes from those previously calculated and possibly explain the three hours delay of the observed phases from the computed values.
\end{abstract}

Ruassunto. -.. Si prende in esame la funzione di eccitazione termica delle maree atmosferiche $J$, per l'assorbimento della radiazione solare da parte del vapor acyueo, secondo il modello derivato da Siebert. I a formula di Mugge-Holler per l'assorbimento da parte del vapor acqueo viene integrata numericamente utilizando i dati sperimentali per la concentrazione di vapore nella troposfera e nella stratosfera. I risultati mostrano che la formula di siebert fornisce una ragionevole approssimazione nella bassa troposfera, ma sopravvaluta esageratamente il riscaldamento dovuto al assorbimento da parte del vapore acqueo, nellalta troposfera e nella stratosfera. Sembra probabile pertanto che, impiegando il corretto profilo verticale di $J$, le ampiezze o le fasi delle oscillazioni diurne della temperatura e della velocita del vento di marea potrebbero subire variazioni significative rispetto a quelle calcolate precedentemente, a potrebbero spiegare eventualmente il ritardo di tre ore osservato nelle fasi rispetto ai valori caleolati.

(*) Istituto di Fisica - Lniversiti di Bologna. 


\section{INTROHETION}

The atmospheric tide is an atmospheric oscillation with period of one solar or lunar day or their integral fractions. Both the sun and the Moon produce in fact, tirlal forces on the Earth's atmosphere and give rise to periodical, primary horizontal, air motions which are related to periodical variations in pressure, density and temperature.

The tidal wind speeds at ground level are only at few $\mathrm{cm} / \mathrm{sec}$ and are very difficult to detect in presence of much larger meteorological winds, but the phenomenon of tidal amplification, resulting from the upper decrease in air rensity, auses a nearly exponential increase in wind speeds which reach $30 \mathrm{~m} / \mathrm{sec}$ at $100 \mathrm{~km}$ altitule.

Barometric oscillations at gromnd level were the earliest obserrational fact to be recorden and were probably known since the 17 th century. Barometric recordings at tropical latitudes show a twelvehourly oscillation in pressure with amplitule of $1.2 \mathrm{mb}$ and maxima at about 10 a.m. and 10 p.m. local time. At mid and high latitudes this oscillation is concealed by the much higher, irregular meteorological processes but it can still be detected through hamonic analysis applied to many days of data.

Pressure oscillations with periods of 24 his, 8 lors and 6 hiss are also revealed from hamonic analysis, but the semidimmal component is the largest in amplitude and the most regular in geographical distribution.

Lunar almospheric tides are very much smaller than solar tides. Their average amplitude is only one fifteenth of the semidiurnal tide. Innar tides are letectable at tropical stations from barometric recordings but about one year of data is neederl for a reliable determination. Nevertheless lunar tides play a signifioant role at high levels and have great theoretical interest in the study of the atmosphere since they are due only to gravitational somess which are known exactly.

\section{THE THDAL EQTTTONS}

At ground level the barometric oscillations provisle the principal data on atmospheric tides and the amplitudes of the various periodical terms are summarized by means of empirical functions of latitude, longitule and time [Haurwitz (10,11)]. 
Let $S(p)$ denote the solar pressure oscillation; then

$$
S(p)=\sum_{\lambda=1}^{12}\left(a_{\lambda} \cos \lambda t^{*}+b_{\lambda} \sin \lambda t^{*}\right)=\sum_{\lambda=1}^{12} c_{\lambda_{n}} \sin \left(\lambda t^{*}+\varepsilon_{\lambda}\right)=\sum_{\lambda=1}^{12} S_{\lambda}(p)
$$

where: $\lambda^{\cdot 1}$ is the periorl of the harmonic component in days,

$t^{*}$ is the local mean time in degrees,

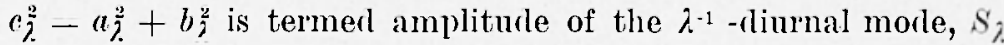

$\varepsilon_{\lambda}=\operatorname{atan} a_{\lambda} / b_{\lambda}$.

Once the analysis of $s(p)$ has been carried out at a large number of stations regularly distributed in latiturle and longitude, its planetary representation can be obtained. Unfortunately the geographical ristribution of the observing sites is not as even as it would be desirable but an expansion in, say, spherical harmonies, is not difficult to obtain for the more regular oscillations. For the purpose of tilal oscillations however, an expansion in Fourier polynomials in longitude $\varphi$ and in Hough functions $\Theta_{n}$ in colatiturle $\vartheta$ for each $\lambda^{-1}$-rlinmal component, is best suited, e.g. in Chapman-Iindzen (6). Substituting universal time $t$ for local time $t^{*}$ according to the relation:

we finally obtain

$$
t=t^{*}-\varphi
$$

$$
\begin{aligned}
& S_{\lambda}(p)=\sum_{s=-\infty}^{+\infty} \sum_{m=s}^{+\infty} K_{\lambda, m}^{s} \Theta_{\lambda, m}^{s}(\vartheta) \sin \left(\lambda t+S \varphi+\varepsilon_{j, m}^{s}\right)= \\
& =\sum_{s=-\infty}^{+\infty} \sum_{m=s}^{\infty} S_{\lambda, m}^{s}(p)=\sum_{m=s}^{+\infty} S_{s}
\end{aligned}
$$

$S_{\lambda}^{s}$ is termed a wave family and $s_{\lambda . m}^{s}$ a wave trpe following the terminology of Siebert ( $\left.{ }^{27}\right)$.

Tirlal fields $\delta p, \delta \varrho, \delta T, u, v, w$ are assumed to be linearizable perturbations about a basic state $p_{0}, Q_{0}, T_{0}$ with the atmosphere at rest $(u, v, w$ are meridional sonthward, the zonal eastward and the vertical components of the tidal wind velocity $\vec{v}$ in a local reference frame). The relevant equations are supposed to hold for both the perturbed fields $p_{\mathrm{o}}+\delta p, \ldots$ and the basic fields $p_{\mathrm{o}}, \ldots$; furthermore $p_{0}, Q_{0}, T_{0}$ are assumed to be independent of latitude and longiturle so that we can write,

$$
p_{0}(z)=p_{0}(\mathrm{O}) \quad e^{\cdot x}
$$

where $x=\int_{0}^{z}\left(g / R^{\prime} T\right) \mathrm{d} z^{\prime}$ is termed reduced height. 
In a reference frame co-rotating with the Earth and with axes in the meridional direction, toward the South pole, in the East direction and in the rertical direction, the Eulerian equation of motion can be written in spherical coorlinates $r, i, p$, in the form:

$$
\begin{gathered}
\frac{\partial u}{\partial t}-2 \omega v \cos \vartheta=-\frac{1}{R_{E}} \frac{\partial}{\partial \vartheta}\left(\frac{\delta p}{\varrho_{0}}+\Omega\right) \\
\frac{\partial v}{\partial t}+2 \omega u \cos \vartheta=-\frac{1}{R_{E}} \frac{1}{\sin \vartheta} \frac{\partial}{\partial \varphi}\left(\frac{\delta p}{\varrho_{0}}+\Omega\right) \\
\frac{\partial \delta p}{\partial z}=-g \delta n-\varrho_{0} \frac{\partial \Omega}{\partial z}
\end{gathered}
$$

where $(1)=7.292 \cdot 10^{-5} \mathrm{sec}^{1}$ is the angular velocity of the Earth, $\Omega$ is the scalar potential describing the gravitational tide-producing force, $R_{E}$ the Earth' rarlius.

The continuity equation can be written as:

$$
\frac{\partial \delta \varrho}{\partial t}+w \frac{d Q_{0}}{d z}+\varrho_{0} \chi=0
$$

where $\%$ is the velocity divergence expressed in spherical coordinates:

$$
\nabla \cdot \vec{V}=\chi=\frac{1}{R_{E} \sin \vartheta} \frac{\partial}{\partial \theta}(u \sin \theta)+\frac{1}{R_{E} \sin \vartheta} \frac{\partial v}{\partial \varphi}+\frac{\partial w}{\partial z}
$$

Finally we can state the energy equation in terms of $J$ the rate of heating per unit mass of air:

$$
c_{v} \frac{\mathrm{D} T}{\mathrm{D} t}=\frac{R}{\gamma-1}\left(\frac{\partial \delta T}{\partial t}+w \frac{\mathrm{d} T}{\mathrm{~d} z}\right)=\frac{g H}{\varrho_{0}} \frac{\mathrm{D} Q}{\mathrm{D} i}+J
$$

where $e_{v}$ is the specific heat for constant rolume $\gamma=c_{p} / c_{v}=1.4$ $I I=\frac{R T_{0}}{g}$ is termed scale height and the $\frac{D o}{D i}$ term describes the arliabatic heating resulting from the vertical movement of air. 
The ideal gases equation can also be transformed into a linearized form by taking the differential of its logarithm:

$$
\frac{\delta p}{P_{\mathrm{o}}}=\frac{\delta \rho}{\varrho_{0}}-\frac{\delta T}{T_{0}}
$$

Using equation [10] in [9] to eliminate $\delta T$ we obtain:

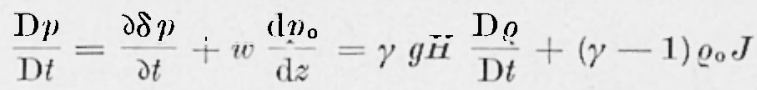

In tidal theory it is convenient to use as fundamental variable the quantity

$$
G=-\frac{1}{\gamma p_{\circ}} \frac{\mathrm{D} p}{\mathrm{D} t}
$$

Now if we let $f=f_{0}+\delta f$ stand for any tidal field, we can write $f$ as a superposition of wave families $f_{2}$, where:

$$
f_{\lambda}^{2}=f_{\lambda}^{s}(\vartheta) e^{i(\lambda t+s \varphi)} \quad \begin{aligned}
& \lambda=1,2, \ldots \\
& s=0, \pm 1, \pm 2, \ldots
\end{aligned}
$$

Then we can replace the operators $\frac{\partial}{\partial t}$ and $\frac{\partial}{\partial \varphi}$ by $i$ and is respectively. Then we can solve immediately the equations [t-5]:

$$
\begin{aligned}
& u_{\lambda}^{s}=\frac{i \lambda}{4 R_{E()^{2}}\left(f^{2}-\mu^{2}\right)}\left(\frac{\partial}{\partial \theta}-\frac{s \cot \theta}{f}\right)\left(\frac{\delta p^{s}}{\varrho_{0}}+\Omega_{\lambda}^{s}\right) \\
& v_{\lambda}^{s}=\frac{-\lambda}{4 R_{E()^{2}}\left(f^{2}-\mu^{2}\right)}\left(\frac{\cos \vartheta}{f} \frac{\partial}{\partial \theta}+\frac{s}{\sin \theta}\right)\left(\frac{\delta l_{\lambda}^{s}}{\varrho_{0}}+\Omega_{\lambda}^{s}\right)
\end{aligned}
$$

where $f=\frac{\lambda}{2(1)}$ and $\mu=\cos \vartheta$

These equations display a singularity at a latitule $\vartheta$ where $|\cos \vartheta|=f$ but this is not reproduced in the complete solutions as Brillouin (3) showed.

Using [13-14] in [8] we obtain:

$$
\chi_{\lambda}^{\delta}=\frac{\partial w_{\lambda}^{s}}{\partial z}+\frac{i \lambda}{4 R_{E}^{2} \omega^{2}} F\left(\frac{\delta p_{\lambda}^{s}}{\varrho_{0}}+\Omega_{\lambda}^{s}\right)
$$


where $F$ is a second order differential operator given by:

$$
F=\frac{1}{\sin \vartheta} \frac{\partial}{\partial \theta}\left(\frac{\sin \vartheta}{f^{2}-\mu^{2}} \frac{\partial}{\partial \vartheta}\right)-\frac{1}{f^{2}-\mu^{2}}\left(\frac{s}{f} \frac{f^{2}+\mu^{2}}{f^{2}-\mu^{-}}+\frac{s^{2}}{\sin 2 \theta}\right)[10]
$$

Equations [15-1๖-11-7-6] constitute a set of 5 differential equations in the five unknowns $\delta p, \delta o, r, \chi, w$, which can be rerlucerl to a single equation for $\boldsymbol{G}$ alone:

$$
\begin{aligned}
& H \frac{\partial 2\left(r_{z}^{s}\right)}{\partial z^{2}}+\left(\frac{\mathrm{d} H}{\mathrm{~d} z}-1\right) \frac{\partial\left(r^{8}\right)}{\partial z}-\frac{\mathrm{i} \lambda}{g} \frac{\partial^{2} \Omega}{\partial z^{2}}= \\
& =\frac{g}{4 R_{E^{(1)^{2}}}^{2}} F^{\prime}\left\{(l H+k)\left(r_{;}^{\delta}-\frac{l}{\gamma y^{H}} J_{i}^{\delta}\right\}\right.
\end{aligned}
$$

where $k=\frac{\gamma-1}{\gamma}=\frac{2}{i}$.

In the shallow atmosphere approximation, rariations of the tirlal potential $\Omega$ within the atmosphere can be neglecterl, since the sale length for variations of $\Omega$ is the Moon-Earth or the Sun-Earth distance.

Equation [17] can be solved by the method of separation of the variables assuming for $a^{8}>$ a solution in the form:

$$
G_{\lambda}^{s}=\sum_{s} L_{\lambda_{n}}^{s}(z) \Theta_{\lambda_{n}}^{n_{1}}(\vartheta)
$$

If we assume the $\left\{()_{i n}^{s}(\vartheta)\right\}$ all $n$ set to be complete for $0 \leqslant \vartheta \leqslant \pi$ then $J$ may be expander as:

$$
J_{\lambda}^{g}=\sum_{n} J_{\lambda n}^{g}(z) \Theta_{\lambda, n}^{s}(\vartheta)
$$

and substitution of [18-19] into [17] yields the following set of equations for $L_{j_{n}^{*}}^{*}$ and $\Theta_{i_{n}}^{\delta}$ separately:

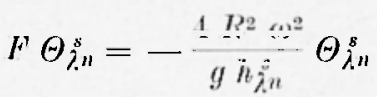

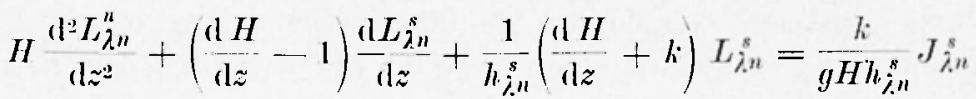

where $1 / h_{\lambda_{n}}^{s}$ is the constant of separation and $h_{\lambda_{n}^{s}}^{s}$ is termed equivalent depth.

Equation [20] is known as Iaplace equation and its solutions as Hough functions; eq. [थ2] is termed rertical structure equation 
or rarlial equation and the knowlerge of the thermal structure of the atmosphere is neerlerl to find its solutions.

The boundary conditions to be imposed on equation [20], i.e. $\Theta_{n}$ bounderl at both poles, define it as an eigenvalue equation whose eigenvalues rletermine the $h_{n}$ 's. From now on we shall irop the suffixes $\lambda$ and $s$, their presence being understoor in all the following formulae. Equation [21] may be transformerl into a simpler equation, more suitable for numerical integration, using the substitution:

$$
L_{n}=e^{x / 2} y_{n} \quad \text { where } x=-\log \frac{p_{\circ}(z)}{p_{0}(O)}
$$

then we obtain:

$$
\frac{\mathrm{d} l \cdot y_{n}}{\mathrm{~d} z^{2}}-\frac{1}{4}\left|1-\frac{4}{h_{n}}\left(k H+\frac{\mathrm{d} H}{\mathrm{~d} x}\right)\right| y_{n}=\frac{k}{\gamma g \mu_{n}} J_{n} e^{-x / 2}
$$

The reason for applying the transformation [2:2] is that according to the law of tirlal amplification, $y_{n}$ may be expecterl to be fairly constant in magniturle at all altiturles.

We can now write the solutions for the other tirlal fields in terms of $\Theta_{n}$ and $y_{n}$ since, if we expand such fields according to the expression:

$$
\delta f=\sum_{n} \delta f_{n}(x) \Theta_{n}(\vartheta)
$$

and similarly: $Q=\sum_{n} \Omega_{n}(x) \Theta_{n}(\vartheta)$,

we obtain, from equations [15-12-11-10- -6$]$ :

$$
\begin{aligned}
& \delta p_{n}=\frac{p_{0}(O)}{H}\left[-\frac{\Omega_{n}}{g} e^{-x}+\frac{\gamma h_{n}}{i \lambda_{n}} e^{-x / 2}\left(\frac{\mathrm{d} y_{n}}{\mathrm{~d} x}-\frac{1}{2}, g_{n}\right)\right] \\
& \delta \varrho_{n}=\frac{p_{\mathrm{o}}(\mathrm{O})}{(g H)^{2}}\left\{-\Omega_{n} e^{-x}\left(1+\frac{1}{H} \frac{\mathrm{d} H}{\mathrm{~d} x}\right)+\right. \\
& +\frac{\gamma^{\prime g h,}}{i \lambda} e^{-x / 2} \mid\left(1+\frac{1}{H} \frac{\mathrm{d} H}{\mathrm{~d} x}\right)\left(\frac{\mathrm{d} y / n}{\mathrm{~d} x}-\frac{1}{2}\right)+ \\
& \left.+\frac{H}{n_{n}}\left(l+\frac{1}{H} \frac{\mathrm{d} H}{\mathrm{dl} x}\right) y_{n}\right]-\frac{l_{i} J_{n}}{i \lambda} \\
& \delta T_{n}=\frac{1}{h} \frac{\Omega_{n}}{H} \frac{\mathrm{d} H}{\mathrm{~d} \mathrm{l}_{r}}-\frac{\gamma q h_{n}}{i \lambda} \sigma^{x / 2} \mid \frac{h_{H} H}{h_{n}}+ \\
& \left.+\frac{1}{H} \frac{\mathrm{d} H}{\mathrm{~d} x}\left(\frac{\mathrm{d}}{\mathrm{d} x}+\frac{H}{h_{n}}-\frac{1}{2}\right)\right) y_{n}+\frac{k J_{n}}{i \lambda}
\end{aligned}
$$




$$
u_{n}=-\frac{i \lambda}{g} \Omega_{n}+\gamma h_{n} e^{x / \Omega}\left[\frac{\mathrm{d} y_{n}}{\mathrm{~d} x}+\left(\frac{H}{h_{n}}-\frac{1}{2}\right) y_{n}\right]
$$

From [13-14-25] it also follows:

$$
u=\sum_{n} u_{n}(x) U_{n}(\vartheta) \quad \text { and } v=\sum_{n} v_{n}(x) \Gamma_{n}(\vartheta)
$$

where:

$$
\begin{gathered}
U_{n}=\frac{1}{f^{2}-\mu^{2}}\left(\frac{\mathrm{d}}{\mathrm{d} \theta}+\frac{s \cot \theta}{f}\right) \Theta_{n} \\
V_{n}=\frac{1}{f^{2}-\mu^{2}}\left(\frac{\cos \theta}{f} \frac{\mathrm{d}}{\mathrm{d} \vartheta}+\frac{s}{\sin \vartheta}\right) \Theta_{n} \\
u_{n}=-\frac{\gamma g h_{n}}{4 R_{\left.E^{(}\right)^{2}}} e^{x / 2}\left(\frac{\mathrm{d} y_{n}}{\mathrm{~d} x}-\frac{1}{2} y_{n}\right) \\
v_{n}=i \frac{\gamma g h_{n}}{4 R_{E()^{2}}} e^{x / 2}\left(\frac{\mathrm{d} y_{n}}{\mathrm{~d} x}-\frac{1}{2} y_{n}\right)
\end{gathered}
$$

The vertical structure equation is an inhomogeneous second order equation and needs two boundary conditions to give the rertical profile associated with a griven Hough mode. At ground level, i.e. at $x-=0$, it is usually assumed that the vertical component of the wind speed is null i.e. that $\omega_{n}=0$ which implies that:

$$
\left.\frac{d y_{n}}{d x}\right|_{x-0}+\left(\frac{H(0)}{h_{n}}-\frac{1}{2}\right) y_{n}(0)=\frac{i \lambda}{\gamma g h_{n}} \Omega_{n}(0)
$$

At the upper boundary the condition of bounded amplitudes as $x \rightarrow \infty$ is used for exponential solutions, and the radiation condition is often employed for oscillatory modes, which assumes that tidal energy can propagate only upward. This assumption is not immune from criticism since downward propagation of tides, due to reflection in the thermosphere or excitation in the thermosphere, has been observed from meteor wind ralar measurements (Spizzichino (28)).

It was not before recent years however, that the nature of the solutions of Iaplace equation has been completely investigated, thanks to the adrent of high speed computers. Cntil the investigations of Kato (13) and Lindzen (18), the equivalent depth had always been supposed to be positive defined in the wake of the origrinal concept of $h$ as the depth of the ocean in Iaplace original equation. Kato 
and Lindzen, independently and almost simultaneously, theoretically predicterl the existence of diumal $(\lambda=1)$ negative morles related to negative equivalent rlepths, which are evanescent in the vertical direction. Negative modes are required in an analytical expression of the observed diurnal barometric variations and their introrluction stands as the mile-stone in the understanding of diurnal tides.

\section{TIIE RESONANCE THEORY}

From the observation that barometric oscillations are relater to the solar day rather than to the lunar day, in contrast with oceanic tirles, Laplace derlucer that the excitation of atmospheric tirles must be thermal in origin.

Kelvin (1-1), from the observation of the semidliumal morle predominance on the diurnal mode, furthermore concluded that the atmosphere responds differently to excitations of different periods and envisagerl a selective resonance amplification of the semirliumal pressure mode, since the temperature oscillation displays a main diurnal component. In the frame of tidal theory, resonance is not only related to the period of the driving force compared to the period of free oscillations of the atmosphere, but also the equivalent depth of the amplifier wave type must be in proximity of the free oscillation eigenvalue $h$ as determined from the homogeneous equation associated with the vertical structure equation, when $J_{n}$ is set equal to zero. Margules (20), assuming a simple morlel atmosphere with constant temperature profile and isothermal changes of state, solved the vertical structure equation and found a qualitative agreement with the resonance theory.

Lamb (15,16) extended the tirlal equations to the case of an autobarotropic atmosphere, i.e. an atmosphere in convective equilibrium with adiabatic (hanges of state, and later found the atmospheric eigenvalue $h=H(O)$ in close proximity to the $s_{22}^{2}$ equivalent depth. Once the selective resonant mechanism was devised to account for the solar semidlurnal preclominance in the barometric oscillations, it was no longer necessary to assume a thermal source of excitation, since the small value of the lunar tide is antomatioally accounterl for in terms of its different period, unsuitable for resonance magnification.

Lamb in fact assumed a gravitational excitation and found that the magnification needed to explain the observed amplitule of the 
solar semi-diurnal oscilation must be $80-90$ times the equilibrium tide, which corresponds to a period of free oscillation not more than two or three min. far from 12 hours. Howerer the phase of maximum amplitude occurs before noon, while the time of maximum graritational excitation is at noon solar time or even later due to friction and inertia of air.

Chapman (5) succeeded in explaining the phase of maximum, which is $155^{\circ}$ at tropical latitudes, introducing also a thermal excitation into play. He assumed the thermal driving force to be due to eddy conductivity from the ground to the lower atmosphere. Using a simple model with constant edcly transport conductivity, chapman found a phase of $195^{\circ}$ for the thermal excitation and concluded that both gravitational and thermal tirles contribute, in nearly equal amounts, to the observed amplitucle. A resonance magnification of about 100 times was needed to match the amplitude.

In the mean time ballon-borne soncles increased the knowledge of the thermal structure of the atmosphere, that turned out to be more complex than assumed by Lamb (16). Bartels (1), assuming a two layer atmosphere, with a constant lapse rate in the troposphere and a constant temperature in the stratosphere, found that the atmospheric eigenvalue $h$ is actually $10 \mathrm{~km}$. The same value was later confirmed by the analysis of the propagation of the pressure wave produced in the Fracatoa explosion in 1883 which excited the free oscillations of the atmosphere. A value of $h=10 \mathrm{~km}$ implies a free period of oscillation of 10.5 hrs for the wave type 5.2 . which is the dominant semidiurnal type, and attempts to reconcile this ralue with the resonance theory, by taking into account the influence of the Cordilleras in West-America, failed to produce a significant change in the value of the equivalent depth $h_{22}^{2}$ associated with $s_{22}^{2}$.

Taylor ${ }^{28}$ ) found a way through such difficulties when he proved that a morlel atmosphere may have more than one eigenvalue and Pekeris $\left.{ }^{26}\right)$, using a 5-layers atmosphere, in order to take into account the mesospheric maximum in temperature, inferred from the observations of anomalous sound propagation, determined an additional eigenvalue $h=8 \mathrm{~km}$.

Unfortunately the actual value of the mesospheric temperature was overestimated by about 50\% and when Jac(chia-Kopal (12), using a correct model atmosphere, repeated the calculation, the $8 \mathrm{~km}$ eigenvalue disappeared and the resonance curve "ame out to be very similar to the one obtained by Bartels with a two-layer atmosphere. Since 
this resonance curve gives the correct value for the lunar semidiurnal oscillation, whose driving force is known exactly, further corrections of the morlel atmosphere seem to be ruler out.

These results definitely disproved the resonance theory and thus also questioned the identification of the driving forces with an eddy conductivity thermal drive combined with a gravitational drive, since without the resonance peak at $8 \mathrm{~km}$ the amplification is not even fourfold.

Once the resonance explanation is ruled out for the observed predominance of solar on lumar tides, the only possibility is to go back to the original suggestion of Laplace who estimated thermal excitation to be the main drive of atmospheric tides. The heating process however must be a more effective one than edly conductivity.

\section{THE THERMOTIDAL FUNCTION}

Siebert $\left({ }^{2 i}\right)$ first discussed the thermotidal excitation by direct insolation of solar radiation absorbed by water vapour in the troposphere.

Water vapour molecules absorb infra-red radiation directly coming from the Sun through many pressure broadened roto-ribrational bands centered at 0.94-1.1-1.38-1.87-2.7-3.2-6.3 $\mu$. The amplitude of the temperature variations due to this periodical heating, is small, but the energy absorbed per unit mass decreases very slowly with altitude. Which makes $\mathrm{H}_{2} \mathrm{O}$ absorption one of the main driving force of ticles in the lower atmosphere. Water rapour can hardly escape the tropopause level, since condensation usually occurs before temperature as low as $220^{\circ} \mathrm{K}$ are reached. The distribution of $\mathrm{H}_{2} \mathrm{O}$ obviously depends on the latitude, the season of the year, the oceanland distribution and the configuration of the meridional large scale convective cells (Goldie (7)) which move in latitude during the year and thus can alter the tropopause level in mid-latitudes; the water vapour concentration then is subject to large seasonal variations in the transition region (Nastenbrook $\left({ }^{21}\right)$ ). The water vapour content in the stratosphere is very low but its measurements are not routinely arailable. $A$ few series of observations have been carried out with instruments especially designed for the high sensitivity and the fast response time required in the stratosphere. Nost of the measurements have been carried out using a frost-point hygrometer flown 
on balloons. Mixing rations measured in this way however, show a considerable range of variation which has been ascriber to contamination of the measuring apparatus from lower levels. Measurements have thus been taken recently, during descent flights and data show a fairly constant mixing ratio ranging from 1 to $4 \mathrm{ppm}$ at each pressure level between $100 \mathrm{mb}$ and $15 \mathrm{mb}$. Values of the specific humidity in the lower troposphere at tropical latitules are given in Newell et al. $\left({ }^{25}\right)$.

The processes of periorlic heating prorluced by the Sun on the rotating Earth are very complex and it is very difficult to give an accurate description of them. Thermal action is introducer in the ticlal equations, precisely in the vertical structure equation, through the thermotialal function $J$ which is a periodic function of time. Absorption of thermal energy procluces an increase in temperature $\tau$ which causes thermal expansion followerl by vertical movement of air, i.e. adiabatic temperature variations $\tau$ so that the actual change in temperature is given by their sum: $T=\tau+\tau^{\prime}$. If the periodic deviation of the temperature from the mean ralue at each level is small, we may neglect the difference between customary temperature and potential temperature. Therefore we can write:

$$
J=c_{n} \frac{\partial T}{\partial t}
$$

where $\tau$ is also a periodic function of time. Expanding $J$ and $\tau$ according to the relations

$$
\begin{aligned}
& J=\sum_{n} J_{n}(z) \psi_{n}(0, p) e^{i, t} \\
& \tau=\sum_{n} \tau_{n}(z) \psi_{n}(i, q) e^{i, t}
\end{aligned}
$$

we obtain:

$$
J_{n}(z)=\frac{i \lambda R}{\dot{k}} \tau_{n}(z)
$$

Where we have used the well known formula $c_{p}=\frac{R}{k}$

The absorption of solar radiation by water rapour, as a mechanism for excitation of atmospheric tides, has been discussed by Siebert (27). The energy absorbed by () gr/cm² of precipitable water vapour under the typical conditions near the ground level can be described through the empirical formula due to Mngge-Moller ( $\left.{ }^{23}\right)$ : 


$$
\begin{array}{lc}
E=E_{\mathrm{o}}(0 \sec \zeta)^{0.3} \cos \zeta & \text { if } 0 \leqslant \zeta \leqslant \frac{\pi}{?} \\
E=0 & \text { otherwise }
\end{array}
$$

where $\zeta$ is the solar zenith angle

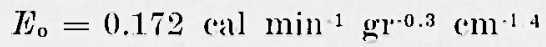

The energy absorption however, depends on temperature and pressure through the absorption coefficient. The linear pressure correction is then applied as given by Moller (22) and the temperature correction is neglected in the definition of the optical thickness $U$ :

$$
L(z)=\int_{z}^{\infty} \varrho_{w}\left(z^{\prime}\right) \frac{p_{\mathrm{c}}\left(z^{\prime}\right)}{p_{\mathrm{o}}(\hat{})} \mathrm{ll} z^{\prime}
$$

where $\varrho_{m}$ is the density of water vapour. The cos 5 term in [38] can be expressed with the aid of spherical trigonometry as:

$$
\cos \zeta=\cos \theta \sin \delta+\sin \theta \cos \delta \cos t^{+} \geqslant 0
$$

where

$\delta$ is the declination of the Sun

$t^{+}$is the solar local time beginning with $t^{+}=0$ at noon.

The time of sun-rise or sunset are then given by $\cos \xi=0$. The thermal energy absorbed per unit mass and unit time is then:

$$
J=\frac{1}{\varrho_{0}} \frac{\partial E}{\partial z}=0.3 E_{0} \frac{\varrho_{w}}{\varrho_{0}} \frac{p_{0}(z)}{p_{0}(\mathrm{O})} U^{-0 . z} \cos ^{0.7} \zeta
$$

When the harmonic analysis of $\cos ^{0.7} 5$ is carried out we obtain, for a given value of $\delta$ and $\theta$, the daily mean absorption and the $\lambda^{-1}$-diurnal variations of the daily absorption:

$$
\begin{aligned}
& B_{0}^{\pi / 2}(\zeta) \cos ^{0.7} \zeta=\sum_{\lambda=1}^{\infty} C_{\lambda}^{+}(\vartheta) \quad \cos \lambda t \\
& \text { where } B_{0}^{\pi / 2}(\xi)= \begin{cases}1 & \text { if } 0 \leqslant \zeta \leqslant \frac{\pi}{2} \\
0 & \text { otherwise }\end{cases}
\end{aligned}
$$

The coefficients $c(\theta)$ are obtained by numerical integration, for various values of the declination, from:

$$
\left.C^{+}=\frac{1}{\pi} \int_{-t_{0}}^{t_{0}} d t^{*}(\cos \theta) \sin \delta+\sin \theta\right)\left(\cos \delta(\cos t)^{0 . \tau} \cos t\right.
$$

where $t_{0}= \pm \operatorname{arcos}(-1 \mathrm{~g} \delta \cot \vartheta)$. Introducing the solar local time begimning at mirlnight $t *$ we can write: 


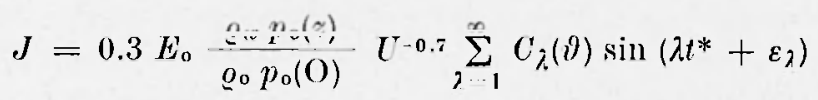

The values of the Fourier coefficients $C_{1}, C_{2}, C_{3}$ are shown in fig. 1 for $\delta=0^{\circ}, 22^{\circ}$ and their values for $\delta=-22^{\circ}$ can be obtained from the values at $\delta=22^{\circ}$ simply by changing $\theta$ in $\left(180^{\circ}-\vartheta\right)$.
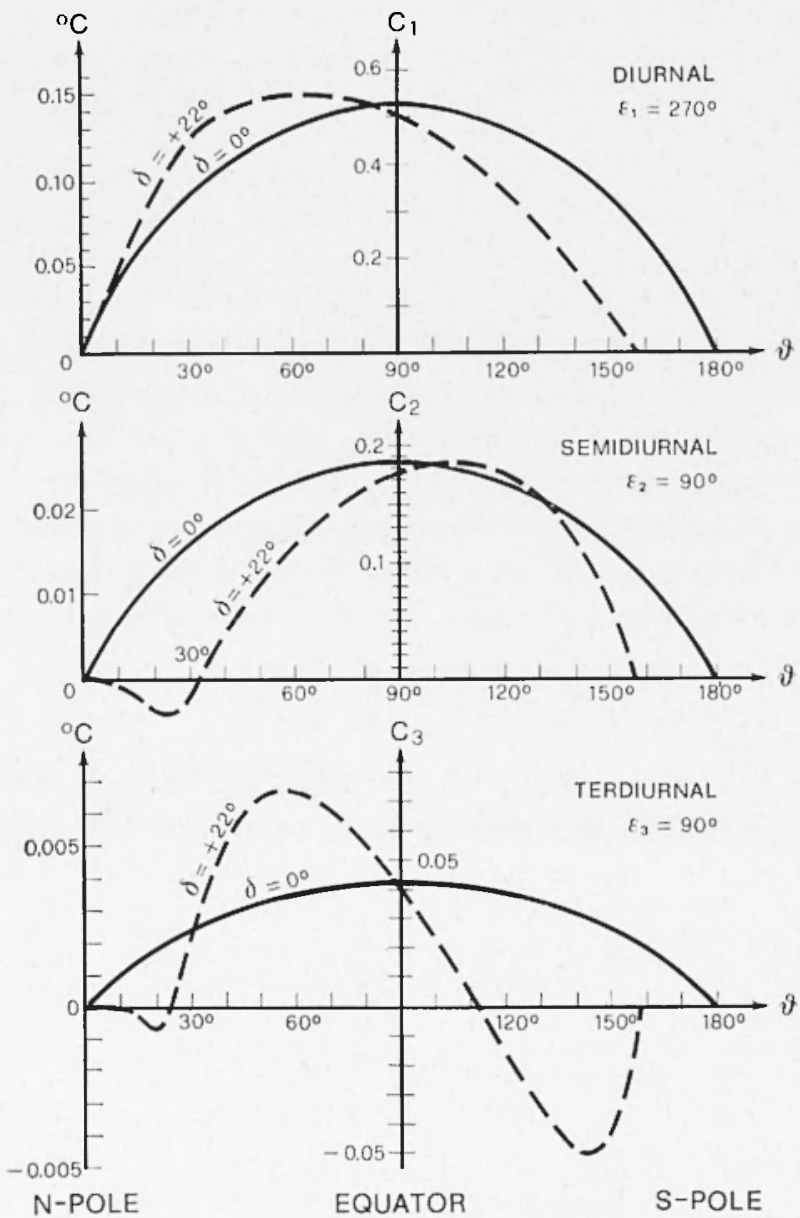

Figr. I - Colatitude distribution of the first three Fourier coefficients 6 ; of daily variation of absorption of insolation by water vapour in the troposphere, determined by analyzing the Mugge-IIoller absorption law for solar dectination $\delta=0^{\circ}$ and $\delta= \pm 22^{0}$, after Siebert $\left({ }^{26}\right)$. The distribution for $\delta=-22^{\circ}$ is obtained by interchenging the hemispheres. The phase constants $\varepsilon$ a have been noted. The leit hand vertical scale is referred to speceifice hunidity conditions of $10^{- \text {- }}$ uniformly on the Earth surface. 
At this point the knowledge of the water vapour alensity distribution in latitude and altitude is needed. Introducing the mixing ratio $q$ defined as the weight of water vapour in the mit mass of air, we can write:

$$
\varrho_{m}(\theta, z)=q(\theta, z) \varrho_{\circ}(z)
$$

Following Siebert we can assume that the dependence of $q$ on latitude and altitude can be separated in the form:

$$
\left.q(\vartheta, z)=q_{0}(\vartheta)\right)(z)
$$

where $\underline{g}_{0}(\vartheta)$ is the mixing matio at ground level.

In meteorology the variable pressure is commonly arlopted as inclependent variable; we can then use the hydrostatic equation to transform the variable of integration from $z$ to $\frac{\hat{t}^{\circ}(\hat{z})}{\nu_{0}(\mathrm{O})}$ in [39]:

$$
\mathrm{d} p_{0}=-\varrho_{0} g \mathrm{~d} z
$$

so that we can write [39] in the form:

$$
U(z)=\frac{p_{0}(O) q_{0}}{g} \int_{0}^{p_{0}(z)} \frac{p_{0}(z)}{p_{0}(0)} r\left(\frac{p_{0}(z)}{p_{0}(0)}\right) d\left(\frac{p_{0}(z)}{p_{0}(0)}\right)
$$

Siebert furthermore assumed a simple power law for $r\left(\frac{p_{0}(z)}{p_{0}(0)}\right)$ :

$$
r\left(\frac{p_{\mathrm{o}}(z)}{p_{\mathrm{o}}(\mathrm{O})}\right)=\left[\frac{p_{\mathrm{o}}(z)}{p_{\mathrm{o}}(\mathrm{O})}\right]^{d}
$$

From the data then arailable about the water vapour content in the troposphere, Siebert found the value of a ranging between 2 and 3 and employed an average value of $a=2.44$ in his calculations. Furthermore he assumed that the water vapour profile followed the approximation [48] up to the top of the atmosphere in order to be able to work out the integral [4i] in closed form. Thus Siebert could eliminate $U$ and $\varrho_{w}$ in [4+] obtaining the result:

$$
J=0.852 E_{0} g^{0.7} p_{0}(O)^{-0.1} q_{0}(9)^{0.3} e^{-x / 3} \cdot \sum_{\lambda=1}^{\alpha} C_{\lambda}(\vartheta) \sin \left(\lambda t^{*}+\varepsilon_{\lambda}\right)
$$

where we have used the well known formula $\frac{p_{0}(z)}{p_{0}(O)}=e^{-x}$. 
Thus siebert foumd that the altitude variations of $J$ occur much slower than in the eddy conductivity model and that water vapour can account for a large portion of the tidal oscillations in the troposphere.

However from analysis of more recent observations which extend the measmement of the mixing ratio for water rapour beyond the troposphere, we have found that, if the assumption [46] can be consiclered a reasonable approximation, the imposition of a simple power law for the vertical distribution of $\mathrm{H}_{2} \mathrm{O}$, is too umealistic.

Thus the dependence of $J$ on altitude may be expected to be significantly affecter by a change in the mixing ratio vertical prolile.

In order to establish the extent of this deviation, we have userl the observational data on the specific humidity reported by NewellKidron-Vincent-Boer $\left({ }^{25}\right)$ at various tropical latitudes from ground level "1) to the $400 \mathrm{mb}$ level. A simple power law inevitably leads to an underestimate of water vapour density at low levels and to an overestimate at higher levels. In order to be able to work out the integral in equation [-17] though, data are needer for the mixing ratio up to the top of the atmosphere. Measmements above the $400 \mathrm{mb}$ level have been carried out with balloon borne, frost point hygrometers, during descent flights at Washington, J.C., Trindad, W.I., and Thule, Greenland, for a period of at least two years. These data were analyzed by Mastenbrook (21) and the average values of the mixing ratios appear to be constant from $140 \mathrm{mb}$ up to $15 \mathrm{mb}$ and independent of latitude. Isarge seasonal rariations are instead present below the $140 \mathrm{mb}$ level, which are related to variations in the tropopause height in the course of the year. We have used these data in orler to extrapolate the specific humidity profile above the $400 \mathrm{mb}$ level at the latitude of Washington in the month of July. The small difference between mixing ratio and specitic humirlity has been neglecterl. This extrapolation, combined with an interpolation in order to increase the density of values in a given height interval, allowed us to work out the optical thickness numerically.

In order to be able to arry out the same analysis at other latitudes, where data are avalable only in the lower troposphere, a third degree polynomial for $y=\log \left(q_{q} / q_{0}\right)$ in function of $x$ was fitter to reproduce the observed values at $400 \mathrm{mb}$ and $100 \mathrm{mb}$, since, as we have previonsly mentioned, the latter value is constant in latiturle. The four coefficients of the cubic $f(x)$ were derived from the four conditions for $f(x)$ to be tangent to the experimental profile at $450 \mathrm{mb}$ and $100 \mathrm{mb}$ : 


$$
\text { at } 450 \mathrm{mb} f(x)=y_{\mathrm{obs}}, \quad \frac{\mathrm{d} f(x)}{\mathrm{d} x}=\frac{y_{500}-y_{400}}{x_{500}-x_{400}}
$$

and at $100 \mathrm{mb} f(x)-y_{\mathrm{obs}}, \quad \frac{\mathrm{d} f(x)}{\mathrm{d} x}=\frac{y_{500}-y_{\mathbf{4 0 0}}}{x_{500}-x_{400}}$

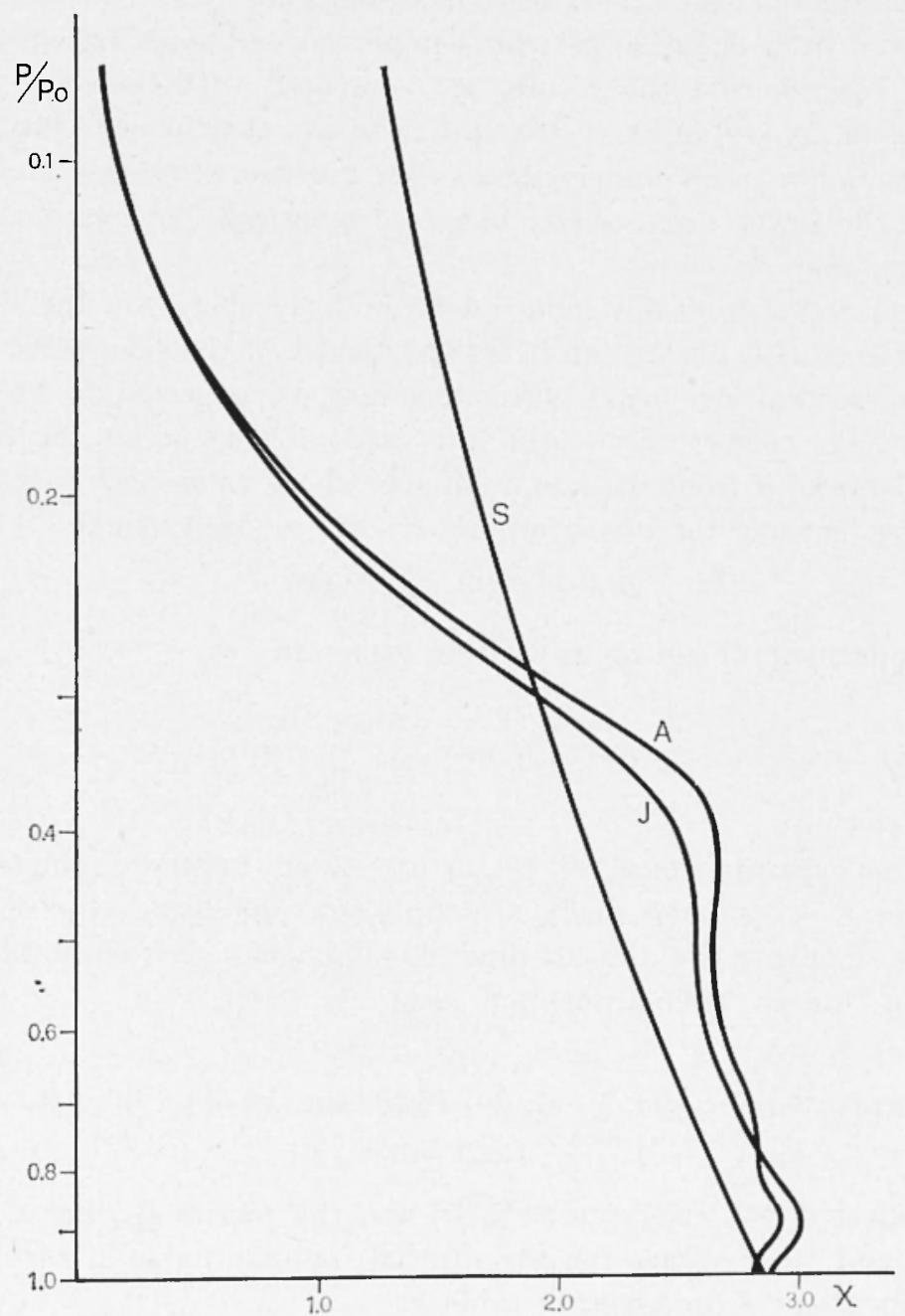

Fig. 2 - Vertical profile of $z$ at the equator. Siebert s profile (s) is compared with profiles resulting from numerical integration of eq. 39] and [44] for cquinoctial (.I) (April) and solsticial (J) (July) eonditions, with a cubic interpolation between $400 \mathrm{mb}$ and $100 \mathrm{mb}$ where experimental datal are lacking. The vertical scale is linear in the reduced hight. 
The interpolation obtained in this way compares farourably with the data arailable at the latitude of Washington in July. This encouraged the extension of the same procedure to other latitudinal belts.

The integral in $[47]$ could thus be worked out numerically applying Simpson rule. The altitude dependence of $J$ has then been calculated from equation [41] for equinoctial and solstitial conditions at the equator and the results are compared with Siebert's profile for $J$ given by [-19] in fig. 2. According to what might have been foreseen, Siebert's result underestimates the function of thermotidal heating in the lower atmosphere, but it dramatically orerestimates its value in upper levels.

Linzen $\left({ }^{19}\right)$ used the morlel derived by Siebert for the diumal drive due to $\mathrm{H}_{2} \mathrm{O}$ absorption in his calculation of the tidal fields below $100 \mathrm{~km}$, so that significant corrections may be expected to be introduced if the correct ralues of $J$ are used. Let us design the vertical dependence of $J$ from altitude, with $\chi(x)$ whose values can be deduced from fig. 2 using the usual formula for the reduced height

$$
x=-\log \left(p_{\circ} / p_{\mathrm{o}}(\mathrm{O})\right) \text {. }
$$

Equation [4t] can be re-written, using [46], as:

$$
J=0.3 E_{0} g^{0.7} q_{0}(\vartheta)^{0.3} p_{0}(O)^{-0.7} \chi(x) \sum_{\lambda=1}^{\infty} C_{\lambda}(\vartheta) \sin \left(\lambda t^{*}+\varepsilon_{\lambda}\right)
$$

Now the expansion of $q_{0}{ }^{0.3} C_{\lambda}(\vartheta)$ in associated Legendre polynomials of order $s=\lambda$ can be easily accomplisher, and using equation [37] we can finally write the $\lambda^{-1}$-diumal component of thermotidal excitation due to $\mathrm{H}_{2} \mathrm{O}$ absorption as:

$$
J_{\lambda}^{s}=\frac{i \lambda R}{i} \chi(x) \sum_{m=s}^{\infty} \tau_{\lambda m}^{s}(O) P_{m}^{s}(\vartheta) \sin \left(\lambda t+s \varphi+\varepsilon_{\lambda m}^{s}\right)
$$

The values of the coefficients $\tau_{\lambda, m}^{\delta}(\mathrm{O})$ and the phases $\varepsilon_{\lambda_{2 m}}^{\delta}$ can be computed and their values for the diumal, semidiumal and ter-dimmal components of $J$ are given in table 1.

The expression [51] for $J_{j}^{s}$ in terms of Hough functiosn, $\Theta_{j, m}^{s}$ can now be easily worked out using the coefficients for the transformation given, e.g., in Chapman-Lindzen $\left(^{6}\right)$. 


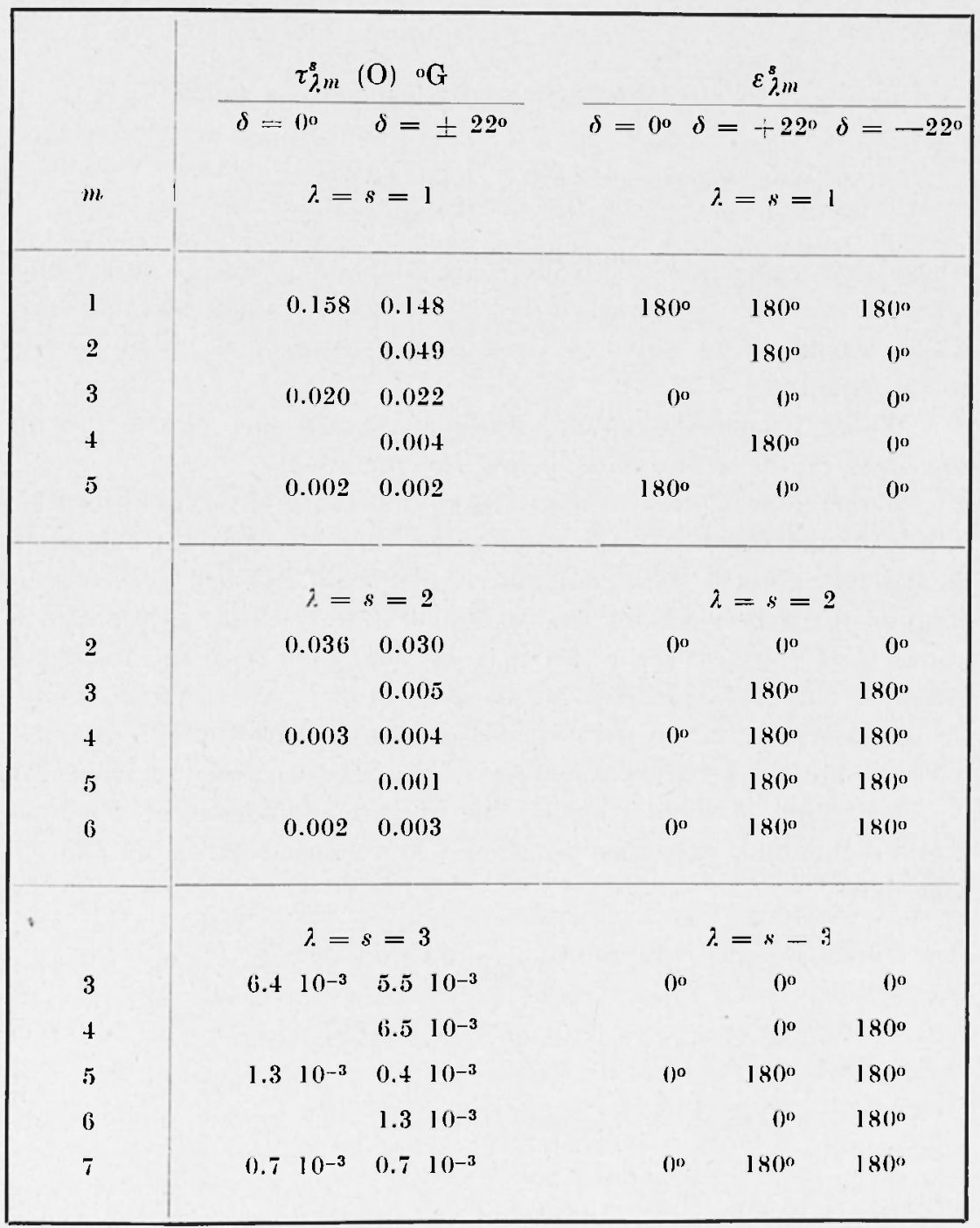

Amplitudes $r_{A m}^{s}(0)$ in Celsius degrees and phases of some important wave families $S^{*}(T)$ of temperature (see equation $[49]$ ) caused by direct absorption of insolation by water vapour for $\delta=0^{\circ}$ and $\delta= \pm 22^{\circ}$, after Siebert $\left({ }^{27}\right)$. 
The diumal component of $J$ is by far the most important and the others will be neglected from now on. Then we can re-write equation [51], using a consistent system of rimensions, i.e. expressing $\lambda$ in $\sec ^{-1}$,

$$
\begin{aligned}
& J_{w}=\frac{i \omega R}{k} \chi(x) \sin (\omega t+\varphi)\left\{0.157 \Theta_{-2}-0.055 \Theta_{-4}+\right. \\
& \left.+0.062 \Theta_{1}-0.016 \Theta_{3}+0.008 \Theta_{5}-\ldots\right\}
\end{aligned}
$$

where the coefficients of the $\Theta_{n}$ 's are in Kelvin degrees and higher order terms have been negrlected together with a small seasonal term which would bring about a contribution asymmetric with respect to the equator.

Water vapour absorption, however is only one of the heating processes in the atmosphere below the mesopause.

We have previously riscussel the importance of ozone absorption in the thermal balance of the mesosphere. In spite of its trace amount, $\mathrm{O}_{3}$ strongly absorbs solar radiation; the energy absorber in a rertical column of air between 30 and $50 \mathrm{~km}$ in the rlirection of the Sun is about $2 \cdot 10^{-4} \mathrm{erg} / \mathrm{cm}^{2} \mathrm{sec}$ which may be compared with the analogous value of only $10^{2} \mathrm{erg} / \mathrm{cm}^{2} \mathrm{sec}$ for $\mathrm{O}_{2}$ absorption. An empirical morlel for $\mathrm{O}_{3}$ absorption in the stratosphere and mesosphere which reprorluces with considerable accuracy the observations has been given by Jeory (17).

Accorling to such a morlel, the riurnal component of the thermotirlal function, expanded in Hough functions, is given by the expression:

$$
\begin{aligned}
& J o_{3}=\frac{i \omega R}{k} e^{0.0116\left(z-z^{\prime}\right)} \sin \frac{\pi}{6 i j}\left(z-z^{\prime}\right) \sin ((0) t+\varphi) B_{z^{\prime}}^{z^{\prime \prime}}(z) . \\
& \left\{1.6308 \Theta_{-2}-0.5128 \Theta_{-4}+0.5+47 \Theta_{-1}+\right. \\
& \left.-0.1411 \Theta_{3}+0.0723 \Theta_{5}-\ldots\right\}
\end{aligned}
$$

where $z^{\prime}=18 \mathrm{~km} \quad z^{\prime \prime}=78 \mathrm{~km}$

$$
B_{z^{\prime}}^{z^{\prime \prime}}(z)= \begin{cases}1 & \text { if } z^{\prime} \leqslant z \leqslant z^{\prime \prime} \\ 0 & \text { otherwise }\end{cases}
$$

In [52] as in [53] seasonal variations have been neglected together with higher order terms. 
Equations [53] and [49] were used by Lindzen (19) in his calculation of the diurnal tidal fields and gave a satisfactory agreement with the observed ampliturles of the tidlal wind speeds in the stratosphere and mesosphere.

\section{CoNClusions}

The rertical structure associated with a particular Hough morle can be inferred using an analogy between the homogeneous equation associated with the rertical structure equation [23] and a wave equation with a dispersive refractive index proportional to:

$$
n=\left\{\frac{1}{4}\left[1-\frac{4}{h_{n}}\left(k H-\frac{\mathrm{d} H}{\mathrm{~d} x}\right)\right]\right\}^{1 / 2}
$$

From this wave analogy we see that the value of $h_{n}$ determines the nature of the vertical structure of a given Hough morle: oscillatory solutions of the homogeneous equation require $n^{2}<0$, i.e. $h_{n}>0$, while a negative equivalent depth results in $n^{2}>0$ and yields an exponential solution.

Since the works of Siebert (27) and Butler-Small (4) the amplitude of the semi-diurnal barometric oscillation, was satisfactorily well understood in terms of water rapour and ozone heating. However, once the resonance explanation is ruled out, the question again arises as to why the more strongly driven diurnal tide gives rise to smaller pressure oscillations than the semi-diurnal tidle. It becomes apparent that, in contrast with the earlier attitude of the resonance theory, it is the cliurnal morle that behaves in a peculiar way. Butler-Small, ignoring the existence of negative Hough morles, observer that the diumal tide is associated with the small equivalent depths $h_{h_{1}, h_{3}, h_{5}}$ and thus argued that, the vertical wavelength being proportional to the $h_{n}$ 's, the diurnal tide is suppressed near the ground by destructive interference of modes exciter in different levels of the ozonosphere. After the finding of the existence of negative modes (Kato $\left({ }^{13}\right)$ and Lindzen ( $\left.{ }^{18}\right)$ ), it became clear that, although the explanation of ButlerSmall may contribute to the damping of the oscillatory components of $J_{1}^{1}$, the principal reason for the observed small amplitucle of the diurnal pressure oscillation near the ground is of a more fundamental origin: the diurnal drives for ozone and water vapour heating, as given by [5:2] and [53] show that most of the diumal excitation goes into 
the negative morles $\Theta_{-2} \Theta_{-4}$ which are evanescent in the vertical direction. Physically this means that the energy of these modes is trapperl within the level of excitation and cannot propagate from the drive level to the ground. In contrast, the semi-rliurnal modes all propagate relatively free.

Still the understanding of diurnal tides cannot be considered fully satisfactory. The main problem still left to be solver is the shift of the rertical profile of the theoretical phases from the observer profile. Theoretical temperature and wind speeds maxima occur about 3 hours earlier than maxima observed at Natal, although the general trend is well reproduced.

Groves $\left(^{8}\right)$ examined the possible causes for such displacement allowing tropospheric and stratospheric heating by $\mathrm{H}_{2} \mathrm{O}$ and $\mathrm{O}_{3}$ to maximize at dlifferent times instead of at local noon and simultaneously, as was previously assumed by Linzen $\left({ }^{19}\right)$. Using the Natal grenadesounding data (Groves ( $\left.{ }^{9}\right)$ ) and assuming alternatively one of the two thermal sources to be exactly known, he found that, if the stratospheric heating maximizes a bit more than 1 hour before the tropospheric heating, the discrepancy between observer and calculated phases is removed. However the physical reason why $\mathrm{O}_{3}$ heating should maximize earlier or $\mathrm{H}_{2} \mathrm{O}$ later than noon is not apparent. Then, if we drop the assumption of different times of maximum for $\mathrm{H}_{2} \mathrm{O}$ and $\mathrm{O}_{3}$ heating, we are compelled to revise the morlels of thermo-tidal processes or even to revise the assumptions of the classical theory, to include dissipative processes or background winds in the lower atmosphere. However the observations at Natal actually confirm that dissipative processes are unimportant below the mesopause. In riew of its simple dependence on solar zenith angle the ozone heating morlel may be considered reasonably correct. Thus it seems possible that at least some of the discrepancies can be accounterl for by a change for the height dependence of tropospheric heating from Siebert formula [49] to formula [51].

It may well be, also, that other heating processes, usually ignored or neglecterl, play a significant role in the thermal excitation of the lower atmosphere. Among these, absorption of solar radiation by suspenderl particulate matter (aerosols) in the troposphere and lower stratosphere must be mentioned. Aerosols are injected into the atmosphere after big volcanic eruptions which can be powerful enough to throw dust into the stratosphere where their life-time is very long due to the absence of any efficient means of removal. Human activity 
also contributes to increase the dust content over inclustrial regions. Howerer the aerosols have spatial variations of concentration, composition, shape, size distribution and index of refraction which are still poorly known. These particles scatter and absorb orer the entire visible and infra-red region of the solar spectrum and may act as nucleation centers for cloud formation, which can further alter the absorption of radiation in the troposphere by altering the cloudiness. Dust reflects a small but significant fraction of the incident solar radiation back into space and may result in a cooling or heating of the atmosphere depending on the optical properties of the particles involved. Braslau-Dave $\left(^{2}\right)$ have considered the effect of aerosols on the total solar energy absorbed, reflected and transmitted by realistic model atmospheres but devoted their study mainly to long-term variations. The NASA (1971) BOMEX experiment (24) investigated the aerosol absorption at low latitudes and found that it may well account for a large fraction (between 15 and $50 \%$ ) of the solar energy absorbed in the lower troposphere below $300 \mathrm{mb}$. Howerer, in view of the still poor knowledge of aerosol properties and distribution the thermotidal function for clust absorption of solar radiation has not yet been included in the tidal theory, although it is surely not permissible to neglect it completely.

\section{ACKNowlengenExts}

This work was done when the author attended the University College of London with the support of an E.S.R.O. postgraduate fellowship. The author wishes to thank prof. G. V. Groves for having stimulated his interest in the subject of atmospheric tides.

\section{REFERENCEN}

(1) BaRTEls J., 1927. - "Ahh. Preuss. Metcorol. Inst.", 8, no. 9.

(2) Brastau N. \& Dave I. Y., 1973. - "J. Appl. Meteor.", 12, p. 601.

(3) Brillouix Ml., 1932. - "Compt. Rend. Acarl. Sci." Paris, 194, p. 801.

(4) BUTLER \&. T. \& SMALL K. A., 1963. - "Proc. Roy. Soc.", A274, p. 91.

(5) CHAPMAN S., 1924. - "Quart. I. Roy. Heteorol. Soc.", 50, p. 165.

$\left.{ }^{6}\right)$ CHapmax S. \& JiNozex R. S., 1969. - "space sci. Rer.", 10. p. 3.

(7) Golde A. H. R., 1950. - "Cent. Proc. Roy. Meteor. Soc.", p. 175. 
$\left({ }^{8}\right)$ Groves (x. V., 1974. - "J. Brit. Interplanet. Soc.", 27, p. 499.

$\left({ }^{9}\right)$ Groves G. V., 1975. - "J. Atmos. \& Terr. Phys.", 37, p. 1133.

(19) Haurwitz B., 1956. - "Meteorol. Pap.", 2, no. 5.

(11) HaUrwitz B., 1965. - "Mrchiv. Meteorol. Geophys. Bioklinatol.", A14, p. 361 .

(12) Jacent L. (4. \& Kopal Z., 1952. - "J. Heteorol.", 9, p. 13.

${ }^{(13)}$ KAто S., 1966. - “J. Geophys. Res.”, 71, p. 3601.

(14) Kelvin LorD, 1888. - "Proc. Roy. Soc. Edinburgh.", 11, p. 396.

$\left({ }^{15}\right)$ Lasв II., 1910. - "Proc. Roy. Soc. London.", A84, p. 551.

(16) LAмв II., 1916. - "Hydrodynamies.", th ed., CLP' - London.

${ }^{(17)}$ Leovy (., 1964. - "J. Atmos. Sci.", 21, p. 238.

${ }^{18)}$ Linizex R. S., 1966. - "Month. Weath. Rev.", 94, p. 295.

(19) Lindzex R. S., 1967. - "Quart. .l. Roy. Meteorol. Soc.", 93, p. 18.

$\left.{ }^{(20}\right)$ Margules M., 1890. - "Sitzber. Akad. Wiss.", Wien, 101, p. 597.

(21) МАктвхввоок II. J., 197I. - “J. Atmos. Sci.", 28, p. I495.

$\left.{ }^{(22}\right)$ Moltek F., 1957. - "Handbuch der Physik" - S. Flugge ed., 48, p. I 55.

${ }^{(23)}$ Mugie R. \& Molder F., 1932. - "Z. Geophys.", 8, p. 53.

(24) XASA SP 285, 1971. - Remote Measurement of pollution, p. 188.

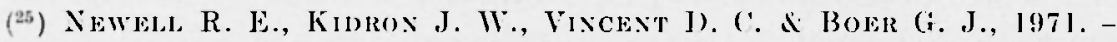
The general eireulation of the tropical almosphere. "MIT I'ress", 1, Canbridge, Massachusets.

$\left({ }^{26}\right)$ Pвкеris (. L., 1937. - "Proc. Roy. Soce.", London, A158. p. 650.

${ }^{27}$ ) SiEpert 11., 1961. - "Advances in Cieoplyys.", 8, p. I05.

${ }^{(28)}$ Sprzzicuno A., 1969. - "Thesis" for D. Sc. Faculty of Sciences Paris tome III.

(29) Tayon G. I., 1936. - "Proc. Roy. Soc.", London, A156. p. 318. 